\title{
Investigation of the Potential for Evaluation of Concrete Flaws Using Nondestructive Testing Methods
}

\author{
Alexandre Lorenzi, ${ }^{1}$ Luciane Fonseca Caetano, ${ }^{2}$ \\ Josue Argenta Chies, ${ }^{2}$ and Luiz Carlos Pinto da Silva Filho ${ }^{3}$ \\ ${ }^{1}$ Civil Engineering Department, The Federal University of Rio Grande do Sul, 9500 Bento Gonçalves Avenue, \\ Building 43436, 91509-900 Porto Alegre, RS, Brazil \\ ${ }^{2}$ The Federal University of Rio Grande do Sul, 9500 Bento Gonçalves Avenue, Building 43436, 91509-900 Porto Alegre, RS, Brazil \\ ${ }^{3}$ Civil Engineering Department, School of Engineering, Federal University of Rio Grande do Sul, 99 Osvaldo Aranha Avenue, \\ 91035-190 Porto Alegre, RS, Brazil
}

Correspondence should be addressed to Alexandre Lorenzi; alexandre.lorenzi@ufrgs.br

Received 9 September 2013; Accepted 12 November 2013; Published 11 May 2014

Academic Editors: X. Li and H. A. Mang

Copyright ( 2014 Alexandre Lorenzi et al. This is an open access article distributed under the Creative Commons Attribution License, which permits unrestricted use, distribution, and reproduction in any medium, provided the original work is properly cited.

\begin{abstract}
Adoption of periodic or continuous monitoring strategies to assess condition state of infrastructure elements is a vital part of service life management (SLM). NDT methods are increasingly seen as an attractive and viable strategy to support condition monitoring. Over the last 15 years, the LEME research group at UFRGS has investigated several aspects related to the use of the ultrasonic pulse velocity (UPV) method and its potential for real field applications. One of the main advances involved the development of artificial neural network (ANN) models for correlating compressive strength and UPV measurements. Another examined problem was how to deal with the large amount of raw data derived from inspection of large structures. Several studies were carried out to check different mapping techniques, as reported by Lorenzi et al. 2011. This paper relates one investigation where UPV and rebound hammer (RH) measurements were collected from a beam containing several induced defects, simulated using different materials. The results were processed using a mapping strategy, which indicated suspicious points where core extraction was undertaken. All cores taken from points derived from UPV results were found to have flaws providing evidence that this may be a suitable tool to assess concrete structures, when data is properly interpreted.
\end{abstract}

\section{Introduction}

Concrete is the most widely used construction material in the world. Preserving its integrity is therefore paramount to achieve the desired service life. However, when concrete is not properly designed or when the production process is inadequately controlled, flaws and defects can be introduced very early in the material. Furthermore, concrete damage may arise as scattered microcracks, due to freeze-thaw or other expansive actions or in the form of localized large cracks due to mechanical or thermal effects, which may extend for significant distances within the structure. All these flaws can affect performance and reduce strength or durability. Given this, it is important to detect and assess their importance as early as possible. That is one of the main reasons why nondestructive testing (NDT) techniques, which are capable of detecting, locating, and characterizing most types of damage, have called the attention of practicing structural engineers, as discussed by Shah et al. [1].

The NDT concept encompasses all test methods used to examine an object, material, or system without impairing its integrity or usefulness. Over the last decades, several NDT methods have evolved from laboratory curiosities to vital quality control tools in different productive fields. These methods are nowadays commonly used to check variations in structure, changes in surface, presence of cracks, or other physical discontinuities, measure the thickness of materials, and determine other characteristics of industrial products.

In civil engineering, NDT methods are becoming very important parts of the recommended inspection procedures 
for several infrastructure objects: bridges, highways, tunnels, and other industrial structures. This demand will probably increase since aging infrastructure requires regular inspections for optimal planning of repair and intervention, in order to ensure performance and human safety [2].

The challenge, therefore, is to assess the potential and learn how best it is to collect, use, and interpret NDT data. The present work reviews one of a series of studies and practical works performed at LEME/UFRGS where ultrasonic pulse velocity (UPV) and rebound hammer (RH) were used to subsidize interpretation and decision making regarding the condition state of concrete structures and the eventual need for intervention.

\section{Nondestructive Testing}

NDT methods are test methods that rely upon physical or chemical principles that can be monitored or measured without significantly affecting the appearance or performance of the analyzed structures. For this reason, NDT methods are favored when testing many structural materials and structures. According to Nesvijski [3], they allow evaluation in situ during service and enable monitoring for an extended period of time.

The application of NDT methods in civil engineering is spreading in several countries. In addition of allowing the evaluation of aged and deteriorated structures, they can also be used for quality control of new structures [4]. In Brazil, the application of these techniques is still restricted, but it is growing rapidly in some sectors. The interest in NDT techniques is rising particularly in inspection of civil engineering infrastructure, mostly made of concrete. Concrete deterioration may be a result of several degradation mechanisms, which may damage the integrity of structures [5]. NDT monitoring techniques are being used to prevent and control the deterioration of concrete structures without damaging the material. The present study proposes a surface mapping technique of UPV and RH data which may be very useful in concrete analysis.

2.1. Ultrasonic Pulse Velocity. Ultrasonic testing is a wellestablished nondestructive technique for the detection of flaws and characterization of materials, based on the monitoring of the propagation speed of an ultrasonic wave throughout the material. During tests, transmitting and receiving transducers are placed on different parts of the object, allowing an ultrasonic pulse to be sent through the material [6]. If a flaw is encountered, the wave is delayed. Using this knowledge, UPV can be used as an assessment tool to help quantify the existence extent and progression of damage in different structures, [7].

Although most applications of this test focus on the inspection of metals, ultrasonic pulse transmission technique has been shown to be useful also for testing concrete elements. UPV have already been applied to new and old structures, slabs, columns, walls, fire damaged areas, hydroelectric structures, pipes, prefab, and prestressed beams [8]. The UPV method is particularly effective, powerful, and flexible, allowing in-depth analysis of material homogeneity.
It is possible to determine concrete uniformity, to control its quality, to follow up the deterioration, to check the presence of internal flaws and voids using UPV, and to make comparisons with reference specimens, it may estimate potential compressive strength. Finally, when regularly used, it may provide data on the development of problems.

The evaluation of ultrasonic results is a highly specialized and complex activity, which requires careful data collection and expert knowledge and sensitivity to obtain reliable diagnosis. In order to map the homogeneity of a structure, it is necessary to interpret and connect a large number of UPV readings. Accurate analysis requires reliable interpretation strategies, but there is not yet a proper widely accepted method to analyze this data. The research related in this work aimed to investigate a strategy to analyse these data using 3D mapping techniques used to build topographic models.

2.2. Rebound Hammer. The rebound hammer test is essentially a surface hardness tester, where an elastic mass is projected against the surface and the rebound is measured, resulting in the RH number [9]. The rebound mass depends on the hardness of the surface against which the mass impinges [10]. Of course there is a relationship between rebound number and surface strength but deducing concrete strength from the RH number must be done with great care, because several superficial effects can affect the rebound without affecting concrete resistance [11]. Despite the weak theoretical relationship between concrete strength and rebound number, several empirical correlations have been created and used, with mixed success.

The key to understand the inherent limitations of the test for estimating strength is recognizing the factors influencing rebound distance. Essentially, it is a complex problem of impact loading and stress-wave propagation. The rebound distance depends on the kinetic energy in the hammer before impact with the shoulder of the plunger and the amount of that energy absorbed during the impact. Part of the energy is absorbed as mechanical friction in the instrument, and part of the energy is absorbed in the interaction of the plunger with the concrete. It is the latter factor that makes the rebound number an indicator of the concrete properties. The energy absorbed by the concrete depends on the stress-strain relationship of the concrete [12].

Nowadays, the RH method is mostly used to make a preliminary assessment of uniformity or to determine suspicious regions where low or damaged concrete may be located. Given the easiness of application, a quick map of large areas can be done in little time. That is the way the test was used in the present study.

\section{Experimental Investigation}

A beam was tested with a portable ultrasound model VMETER and James Concrete Test Hammer (Figures 1 and 2). This period was chosen to minimize the influence of concrete strength variation on the measurements. The size of the objects placed inside the beam varied between 30 and $95 \mathrm{~mm}$. All objects were detected by NDT measurements. The VMETER is widely used and accepted for concrete quality 
TABLE 1: Description of the objects used to induce defects in the beam.

\begin{tabular}{llll}
\hline Type of object & Geometry & Size & Type of defect simulated \\
\hline Styrofoam ball I & Solid & $75 \mathrm{~mm}$ & Honeycomb \\
Styrofoam ball II & Solid & $50 \mathrm{~mm}$ & Honeycomb \\
Tennis ball & Hollow with filling & $62 \mathrm{~mm}$ & Very large air void or honeycomb \\
Table tennis ball & Hollow & $38 \mathrm{~mm}$ & Large air void or placement defect \\
String made of one table tennis ball and two & Partly hollow and partly solid & 23 to $37 \mathrm{~mm}$ & Elongated honeycomb \\
Styrofoam balls & Elongated Rectangular & $15 \times 80 \times 30 \mathrm{~mm}$ Formwork piece \\
Wood piece & Rectangular & $40 \times 30 \times 55 \mathrm{~mm}$ Formwork piece or honeycomb \\
Wood piece II & &
\end{tabular}

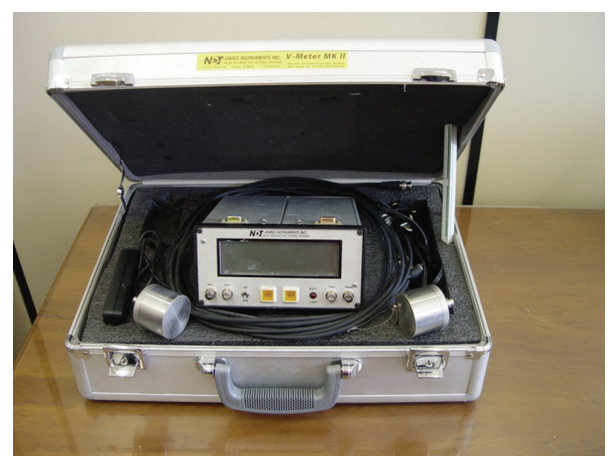

FIgURE 1: Portable ultrasound model V-METER.

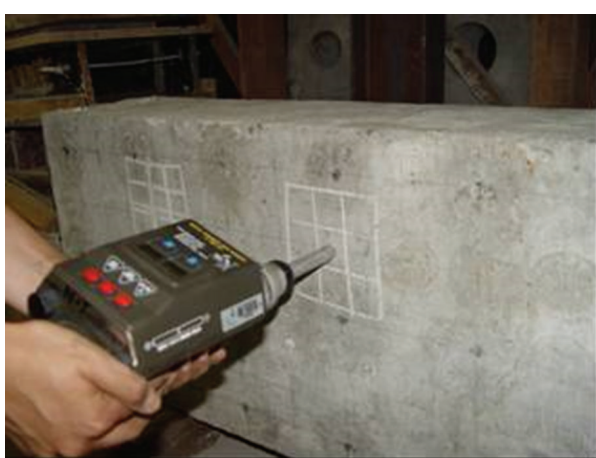

FIgURE 2: Rebound hammer at concrete beam. control and inspection. It measures and correlates concrete strength to a standard strength measurement, allowing nondestructive testing of complete structures [8]. The James Concrete Test Hammer is an advanced, completely automated system for estimating concrete compressive strength. Its calculation, memory, and recording functions allow for quick, easy, and accurate test results. They indicate the compressive strength of hardened concrete [13].

The main objective of the test was to collect data and verify if the analysis of the results could allow the detection of the objects inside the beam. Surface mapping technique was used for interpretation of results, as reported by Lorenzi et al. 2011 [14].

In order to investigate which methods were more accurate to detect the objects inside the concrete beam, one grid was tested. Figure 3 shows one of the faces of the grid. Readings were made around each point. The readings were grouped and generated the reading quadrants. The main issue was to determine the best strategy to organize and to interpret ultrasonic pulse velocity results and rebound hammer results. The software program Surfer 7.0 was used to create a superficial map, with an image generation. Figure 4 shows the beam prepared for performance of the ultrasonic tests. A measurement answer sheet was used to ensure the perfect positioning of the transducers during the tests.

3.1. Materials. The mix proportions used to prepare the concrete beam mixture were $1: 2.57: 3.43$ (cement: natural river sand : coarse basalt gravel), with a w/c ratio of 0.58 . This resulted in a $60 \mathrm{~mm}$ slump and a 28-day compressive strength of $20 \mathrm{MPa}$. The measurements were taken after 1 year using two measurement grids:

(a) a $150 \times 150 \mathrm{~mm}$ square grid, starting at a point located $50 \mathrm{~mm}$ from the bottom and $50 \mathrm{~mm}$ from one of the lateral edges of the beam;

(b) a $75 \times 75 \mathrm{~mm}$ square grid, with four times more cells than the first one, starting at the same point, located $50 \mathrm{~mm}$ from the bottom and $50 \mathrm{~mm}$ from one of the lateral edges of the beam.

Table 1 describes the objects introduced into the beam. In addition rebar elements were also introduced into the beam. Four 1/2" longitudinal steel bars were used to create a supporting cage, together with 3 closed-loop stirrups. Four additional single stirrups were placed in one of the sides of one half of the beam, to check if they would interfere with the UPV measurements. A corroded rebar piece and piece of prestressing tendon were also placed along the main direction of the beam.

The elements are shown in Figures 5 and 6. They were kept in place using nylon threads. Reinforcement bars were placed inside the beam to check if their presence would influence the UPV readings. Figure 6 shows a lateral view of the prototype beam with all objects positioned with the aid of nylon threads. One year after being built, the beam was tested.

\section{Experimental Program}

4.1. Items of Investigation. The present study shows the application of two different NDT to interpret data from 


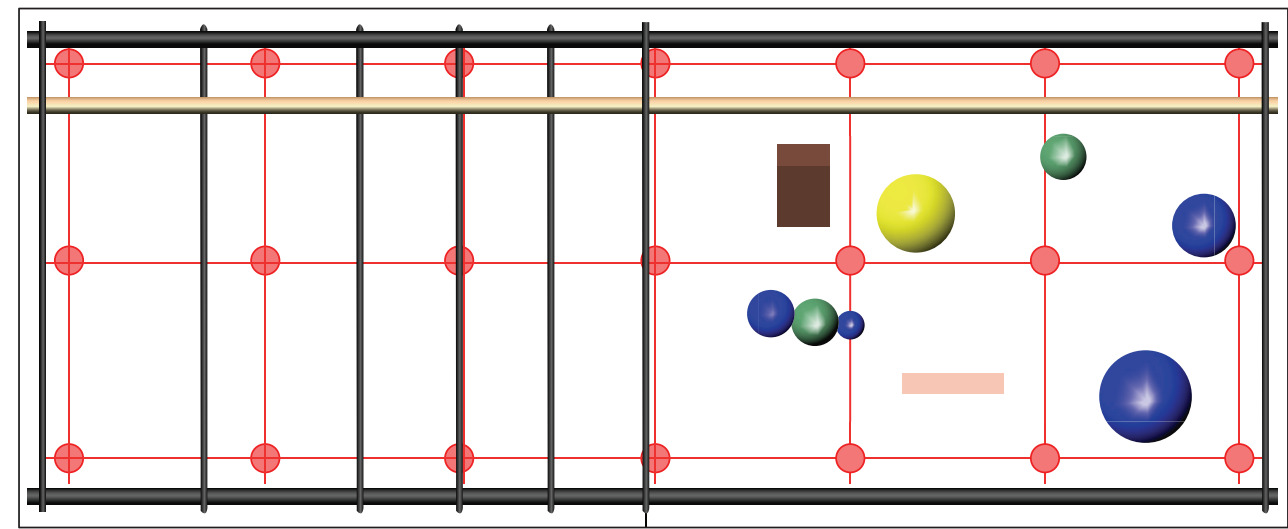

FIGURE 3: Location of the objects into the beam.

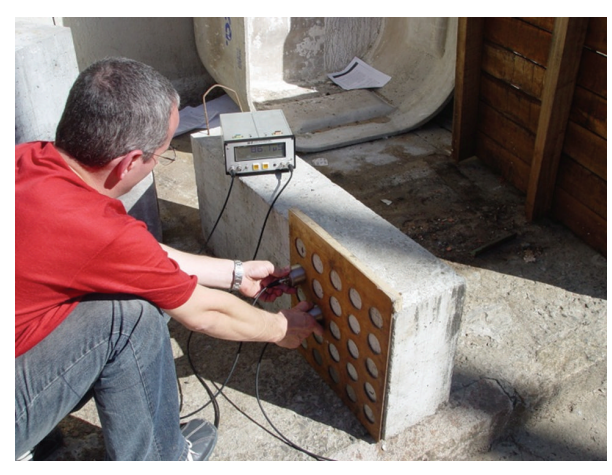

FIGURE 4: UPV measurements at the beam.

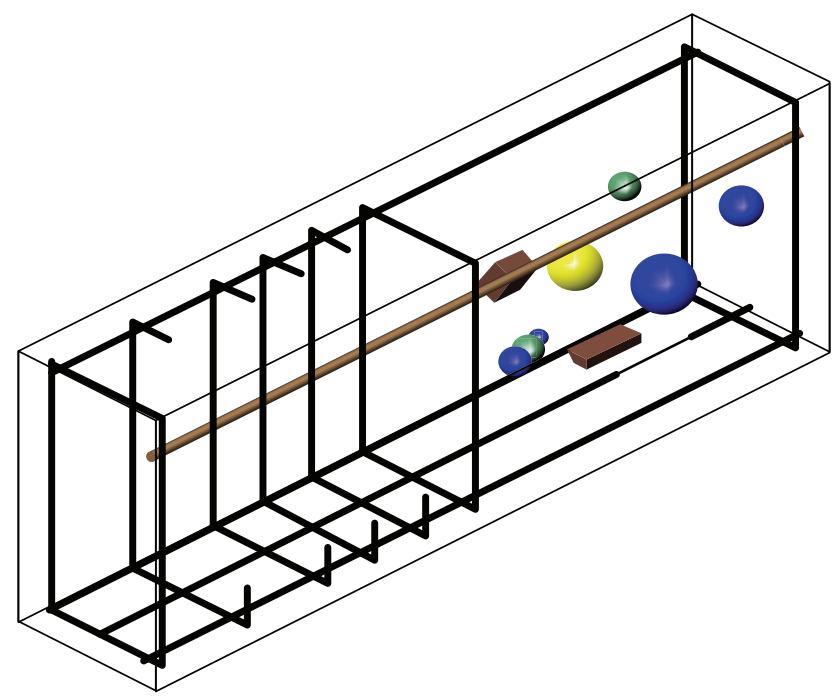

FIGURE 5: Simulation of situations inside the beam.

an experimental beam, measuring $20 \times 40 \times 100 \mathrm{~cm}$, in which some defects were induced. After measurements were performed, the surface was mapped. The objective was to verify the efficiency of defect detection of the applied methods. The collected data were mapped and core samples

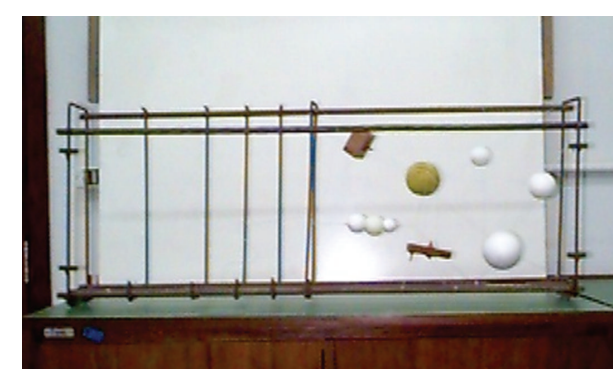

FIGURE 6: Lateral view of the rebar and the objects used to induce defects in the beam.

were taken from the positions that each method pointed out as problematic.

4.2. Surface Mapping. Using a surface mapping software (Surfer 7.0), a contour map of the data was generated. The coordinates of the contour map were the position in the grid (expressed as $X$ and $Y$ values) and the UPV measurement ( $Z$ coordinate). Each indirect measurement was placed at the midpoint of the line connecting two points of the grid.

Adequate intervals were stipulated for the UPV measurement and rebound hammer results in order to create a color map representing the variation of results obtained along the lateral part of the beam. Imaging is implemented in many fields and has been demonstrated to be a powerful tool for the interpretation of signal data. However, imaging for the evaluation of concrete structures has not been widely used. The generated image shows where the readings are lower or higher. When no variations are shown, concrete is homogenous.

\section{Experimental Results}

Contour surfaces were obtained using the surface mapping results. Applying the software program Surfer 7.0, a surface analysis was performed using data obtained in the ultrasonic and rebound hammer tests. The image shows where readings are lower or higher. When no variations are shown, concrete is homogenous. 


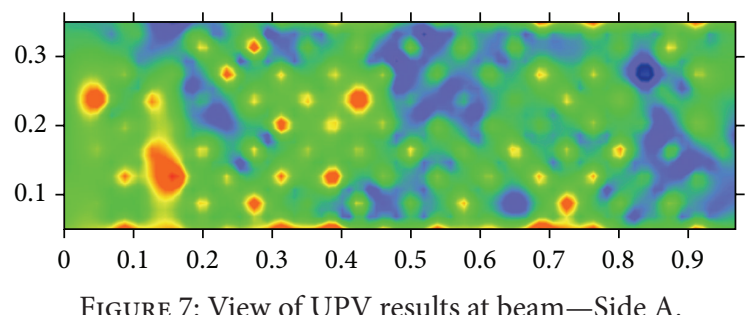

FIgURE 7: View of UPV results at beam-Side A.

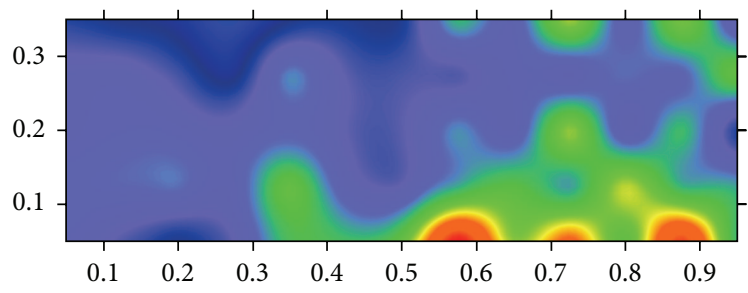

FIGURE 8: View of UPV results at beam-Side A.

In the UPV tests, direct and indirect measurements were taken using the grid. Direct measurements were taken at each point of the grid between the two sides of the beam. The resulting values were placed at the corresponding grid point. Indirect UPV measurements were taken at the four points that made up each grid cell, resulting in 6 UPV values for each face. The four values corresponding to readings taken between two neighboring horizontal or vertical grid points were positioned at the midpoint between these points. An average value was then calculated from the two values corresponding to the diagonal measurements and placed at the center of the square. Finally, five values were placed in each grid cell.

In the rebound hammer tests, after rebound number determination, the resulting value was placed on each point of the grid. A surface mapping software was then used to create continuous colored images, similar to topographic maps, where low and high velocity zones were identified.

Through well-done analysis of the ultrasonic readings and rebound hammer a diagnosis on the concrete state with raised precision can be reached. This research aims to investigate strategies for systemizing and facilitating this analysis.

5.1. Analysis of UPV Test Results. Figures 7, 8, and 9 present the surfaces generated from the UPV tests. The image analysis clearly shows the regions where the readings are lower or higher than the average. The surface generated by the Surfer software program shows the variations in concrete homogeneity, determining the regions inside the beam presenting differences in homogeneity.

The analysis of the surface contour maps created using UPV data indicates that the use of the values obtained by indirect measurements seems to create more accurate images of the known position of the defects. On the other hand, the use of the smaller grid $(75 \times 75 \mathrm{~mm})$ resulted in a more irregular image, which is more difficult to interpret, as shown in Figure 7.

The best results were obtained when the data from the indirect measurements taken with the $150 \times 150 \mathrm{~mm}$ grid

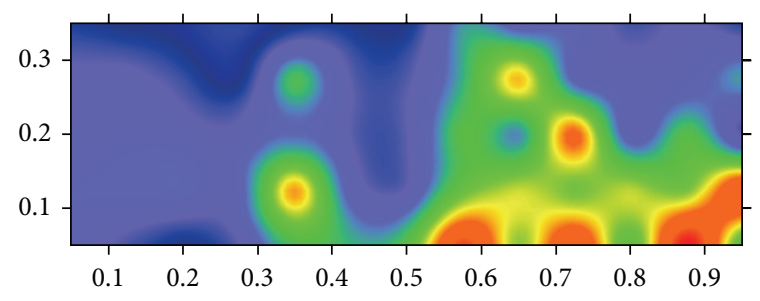

FIgURE 9: View of UPV results at beam-Side B.

were used. Figures 8 and 9 show the images generated with this data corresponding to both sides of the beam. In these images, hotter (red) zones indicate lower UPV values, evidencing the presence of voids or defects. Colder (blue) zones indicate higher UPV values, suggesting more compact zones (or influenced by the presence of the rebar).

In both images, the section of the beam where the defects were induced is clearly identified. The closed loop stirrup in the middle of the beam is also evidenced. The presence of defects or voids that reduce UPV values is unmistakable. The disturbances, as indicated by hotter values, are generally located in the vicinity of the area where the objects were positioned to simulate the concrete defects. It was possible to establish a match between the original position of the defects and the image contour maps.

Despite the uncertainties, the analysis of the contour maps-similar to those that would have been produced if an investigation of a real structure was undertaken-indicates some trends. The presence of the wood pieces and the hollow tennis balls seems to have higher influence on the measurements than the solid Styrofoam balls. The smaller wood piece located nearer to the top of the beam only appears in the side B image, possibly because it was closer to this side of the beam. The presence of the tennis ball is also more marked on this side, and it appears on the side A. The single table tennis ball is only noticeable on the side A image. The defects nearer to the bottom of the beam seem a little displaced but appear on both sides as three evident reductions in UPV values.

The most unexpected result is observed on the left side of both images. There seems to be a disturbance near the middle of the beam, which develops itself vertically. There was no object around this region that could justify such behavior.

5.2. Analysis of Rebound Hammer Results. The rebound hammer results allow generating surfaces that indicates the presence of defects. The obtained results indicate that this test is very useful to locate areas with different concrete surface hardness. With this method, concrete quality in different areas that do not present concrete damage can be compared. However, this method only examines the concrete surface, and therefore its use is relatively limited. The rebound hammer results indicate surface hardness and theoretically seem less capable of detecting the presence of internal defects. Nonetheless, the image contour maps generated with the data collected in these tests are also useful, as shown in Figures 10 and 11 . 


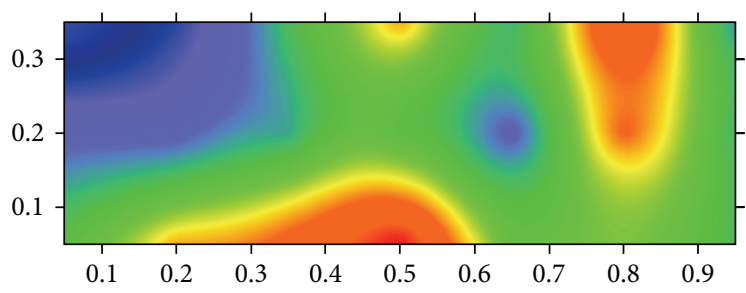

FIGURE 10: View of rebound hammer results at beam-Side A.

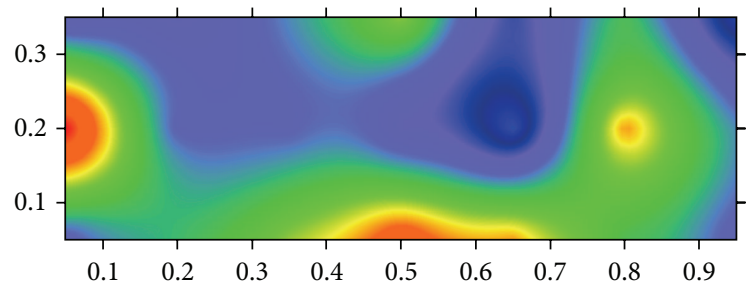

Figure 11: View of rebound hammer results at beam-Side A.

The hotter colors in the images indicate points of low energy rebounds, suggesting softer or more absorbing surfaces, whereas colder colors indicate high energy rebounds or harder surfaces. The images show that the induced defects were located on the right side of the beams, but the results are less clear than those obtained with the UPV data. A strong rebound signal was recorded where the tennis ball was placed. The signal was stronger on the side B of the beam, consistent with the UPV analysis, which indicated that this ball was probably closer to this side. Also, in agreement with the UPV results, the single table tennis ball was only noticeable in the image of side A. The big Styrofoam ball produced a low rebound signal that was noticeable on both sides of the beam. This signal was stronger in the image of side $A$ and was located immediately below the signal traced back to the table tennis ball.

5.3. Concrete Core Analysis. In order to check if the diagnosis made using the contour map images was reliable, core samples were taken at some points chosen based solely on the contour images. Figures 12, 13, 14, 15, and 16 show the extraction results. Figure 12 shows the beam marked with the extraction points. Red circles indicate UPV suspect points, while blue circles indicate RH points. Figures 13, 14, 15, and 16 show some of the extracted cores, providing clear evidence that the defects were accurately located using only NDT data, with no prior knowledge of their position.

\section{Summary and Conclusions}

Based on the results of this experimental investigation, the following conclusions are drawn.

(1) This study demonstrated that NDT tests can be used to locate relatively small defects (around $35 \mathrm{~mm}$ ) in concrete beams that may cause structural performance problems.

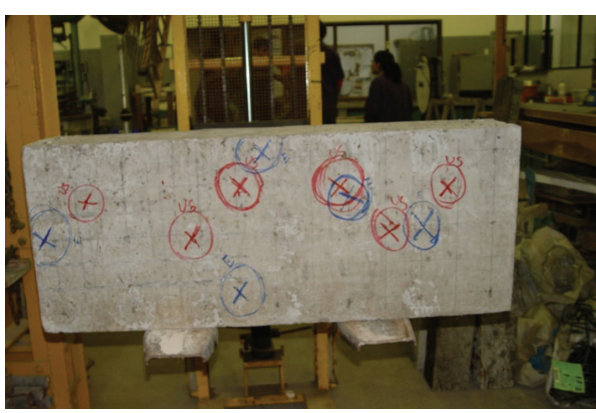

Figure 12: Detail of the marked beam.

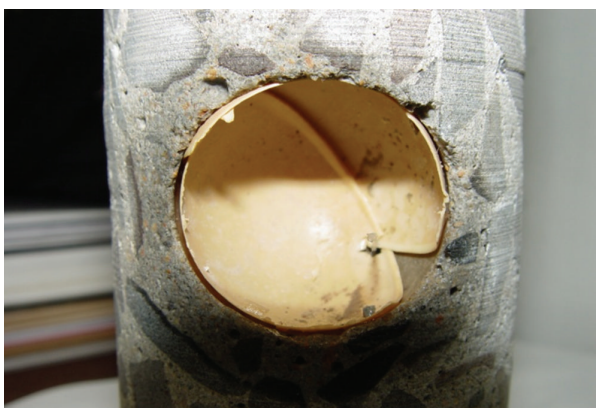

FIGURE 13: Core samples showing the table tennis ball.

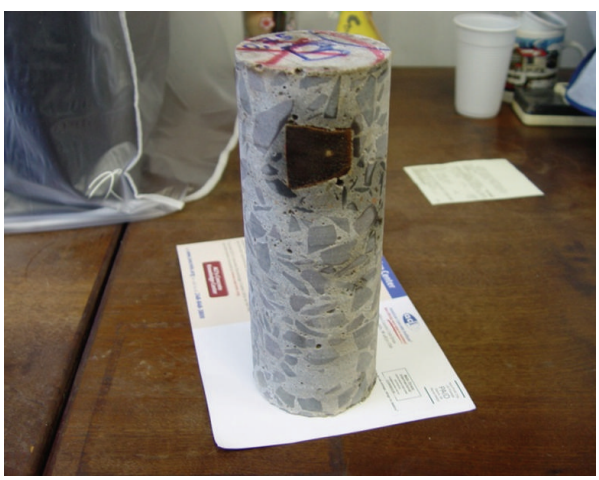

FIGURE 14: Core samples showing the small piece of wood.

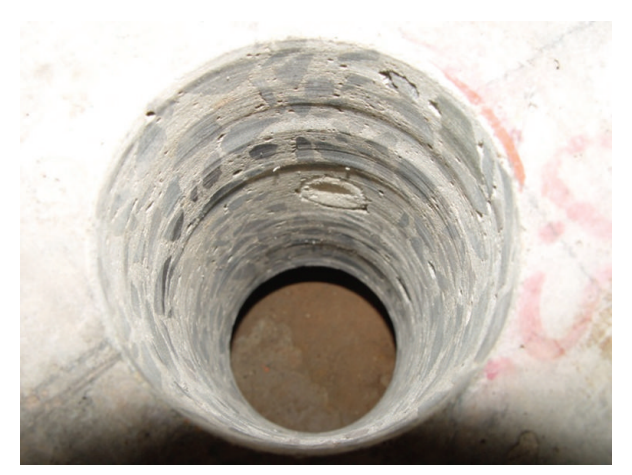

FIgURE 15: Core samples showing the Styrofoam ball. 


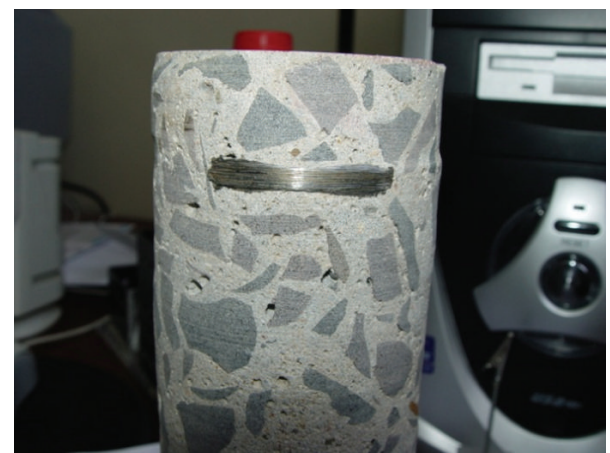

FIGURE 16: Core samples showing the piece of prestressing tendon.

(2) The use of a contour mapping technique was shown to be adequate to organize and interpret the results of a series of NDT tests in order to detect suspicious zones. The use of grids to collect data was adequate to structure the test and ensure that no region was overlooked.

(3) The results obtained in the present study indicated that the use of very small grids may not be a good alternative, because the general signs that indicate the presence of a defect may be masked by the natural variations between concrete zones. The $150 \times 150 \mathrm{~mm}$ grid seemed to provide good accuracy.

(4) It was shown that it was possible to identify the presence of heterogeneous regions inside the tested structure using the strategy of surface mapping. The generation of surface results aided locating the objects inserted in the concrete. Surface analysis allows visualizing internal concrete heterogeneity.

(5) Visualization tools may indicate the location of objects inside concrete structure, suggesting that this may be the best strategy to perform accurate analyses. The combination of UPV and rebound hammer measurements with the mapping software with a visual interface is an efficient method to map concrete homogeneity.

(6) The performed tests showed that ultrasonic tests may be useful for structural analysis. The data obtained allowed the detection of the presence of foreign bodies and voids at the test beam, confirming the potential use of UPV for the inspection of structures. Ultrasonic results provide significant indications of concrete characteristics and of structure homogeneity and quality.

(7) The images generated using indirect UPV measurements were clearer than those generated by direct measurements. This was attributed to the fact that indirect measurements encompass a broader portion of concrete, and the resulting data express the average velocity in an area and not only across the beam.

(8) The rebound hammer results were shown to be sensitive to the surface conditions of concrete elements. This suggests that caution must be taken when using rebound hammer data to determine concrete strength. It is important to highlight that good results were obtained with the rebound hammer data. Further studies should be carried out to check if this simple test can be used, when no other equipment is available, to provide a rough estimate of the presence of defects.

(9) The applied tests demonstrated, with reasonable confidence, the possible presence of defects in the beam, avoiding the need to demolish and rebuild part of the structure, resulting in important cost and time savings.

(10) The coring showed that both tests showed the main defects inserted in the beam, confirming the test diagnosis.

Nonetheless, the usefulness of ultrasonic readings and rebound hammer to detect defects in concrete structures depends on the establishment of a suitable inspection grid. The best investigation strategy, indubitably, is to combine different NDT tests. In the present study, core samples demonstrated that defects were indeed present in the points indicated as suspicious in both tests. In general, the results are that NDT tests can play an important role in determining the existence of defects in concrete structures. Further studies are warranted, however, to establish the reliability and detection threshold of these techniques.

\section{Conflict of Interests}

The authors declare that there is no conflict of interests regarding the publication of this paper.

\section{Acknowledgments}

The authors would like to acknowledge CNPq (Portuguese acronym of the Brazilian Ministry of Science and Technology Agency) for providing an important part of the financial support required to develop this project. The authors would also like to express their appreciation for the technical support given by the research teams of LEME (Portuguese acronym of the Laboratory of Testing and Structural Modeling) of the Federal University of Rio Grande do Sul-UFRGS.

\section{References}

[1] S. P. Shah, J. S. Popovics, K. V. Subramaniam, and C.-M. Aldea, "New directions in concrete health monitoring technology," Journal of Engineering Mechanics, vol. 126, no. 7, pp. 754-760, 2000.

[2] A. Lorenzi, E. G. Nesvijski, P. Sarkis, and J. Sarkis, "Infrastructure NDT monitoring using inspector-computer interface," in Proceedings of ASNT Fall Conference and Quality Testing Show, Phoenix, Ariz, USA, 1999.

[3] E. G. Nesvijski, "Dry point contact transducers: design for new applications," The e-Journal of Nondestructive Testing, vol. 9, no. 9, ID-1745, 2003.

[4] C. L. Nogueira, "Análise Ultra-Sônica da Distribuição dos Agregados no Concreto através de Wavelets," in Proceedings of 
XXI Congresso Nacional de Ensaios Não Destrutivos, pp. 107138, Associação Brasileira de Ensaios Não Destrutivos, Salvador, Brazil, 2002.

[5] S. Shah, K. V. Subramaniam, and J. S. Popovics, "Use of nondestructive ultrasonic techniques for material assessment and in-service monitoring of concrete structures," in Proceedings of the International Symposium on Nondestructive Testing Contribution to the Infrastructure Safety Systems in the 21st Century, pp. 107-114, Universidade Federal de Santa Maria, Torres, Brazil, 1999.

[6] M. Schickert, M. Krause, and W. Müller, "Ultrasonic imaging of concrete elements using reconstruction by synthetic aperture focusing technique," Journal of Materials in Civil Engineering, vol. 15, no. 3, pp. 235-246, 2003.

[7] A. Mirmiran and Y. Wei, "Damage Assessment of FRP-encased concrete using ultrasonic pulse velocity," Journal of Engineering Mechanics, vol. 127, no. 2, pp. 126-135, 2001.

[8] James Instruments, The James V-Meter Mark II, James Instrument Inc., Chicago, Ill, USA, 2009, http://www.ndtjames.com/.

[9] American Society for Nondestructive Testing (ASTM), "Standard test method for rebound hammer number of hardened concrete," Concrete and Aggregates, vol. 04.02, pp. 400-402, 1999.

[10] International Atomic Energy Agency, IAEA-TCS-17: Guidebook on Non-Destructive Testing of Concrete Structures, Vienna, Austria, 2002.

[11] V. M. Malhotra and N. J. Carino, Handbook on Nondestructive Testing of Concrete, CRC Press, 1991.

[12] American Concrete Institute (ACI), "In-place Methods to Estimate Concrete Strength, ACI 228.1R-03," in MCP 2007ACI Manual of Concrete Practice, ACI Committee 228, p. 44, Detroit, Mich, USA, 1997.

[13] James Instruments, James Digital Test Hammers, James Instrument Inc., Chicago, Ill, USA, 2009, http://www.ndtjames.com/ catalog/strengthTesting/jamesdigitaltesthammers.html.

[14] A. Lorenzi, L. C. P. da Silva Filho, J. L. Campagnolo, A. J. Strieder, U. C. de M. Quinino, and L. F. Caetano, "Estudos de Caso sobre Avaliação de Estruturas de Concreto através da utilização de Ensaios Não Destrutivos," Revista ALCONPAT, vol. 1, pp. 196-208, 2011. 

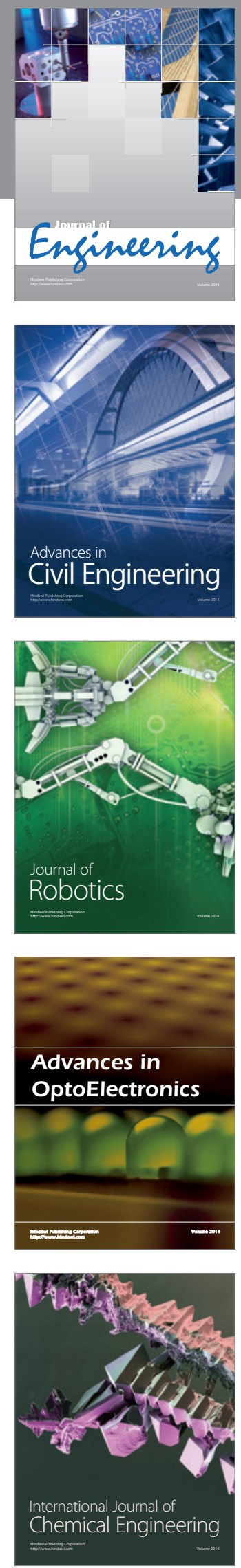

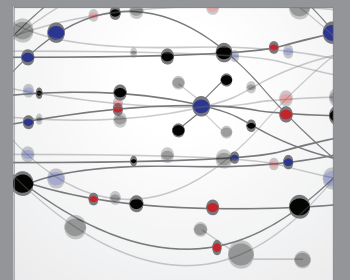

The Scientific World Journal
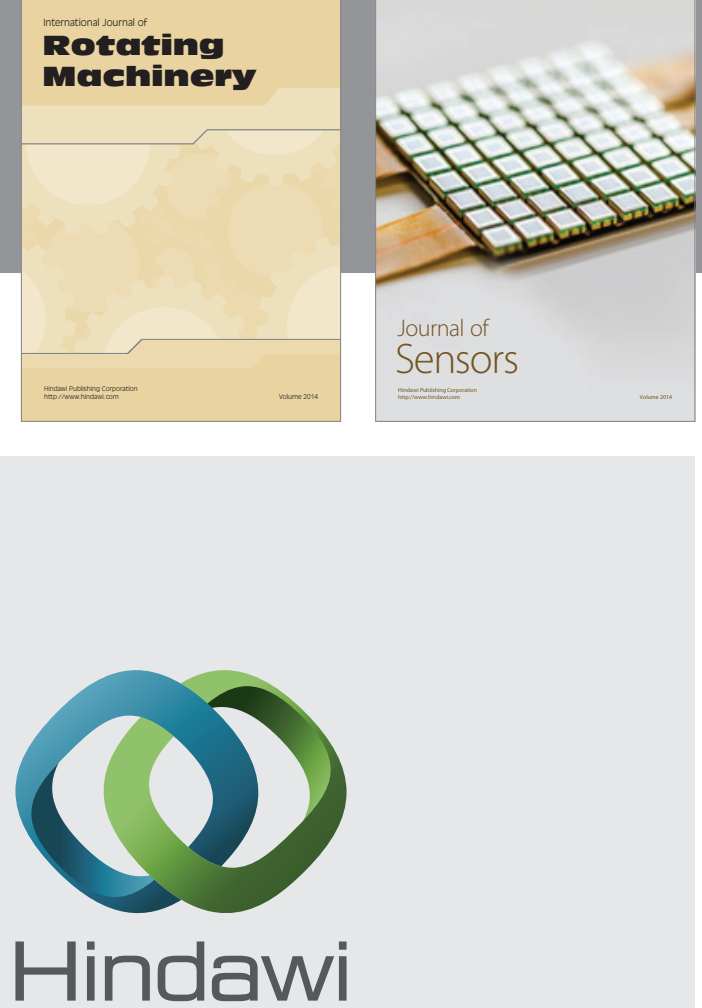

Submit your manuscripts at http://www.hindawi.com
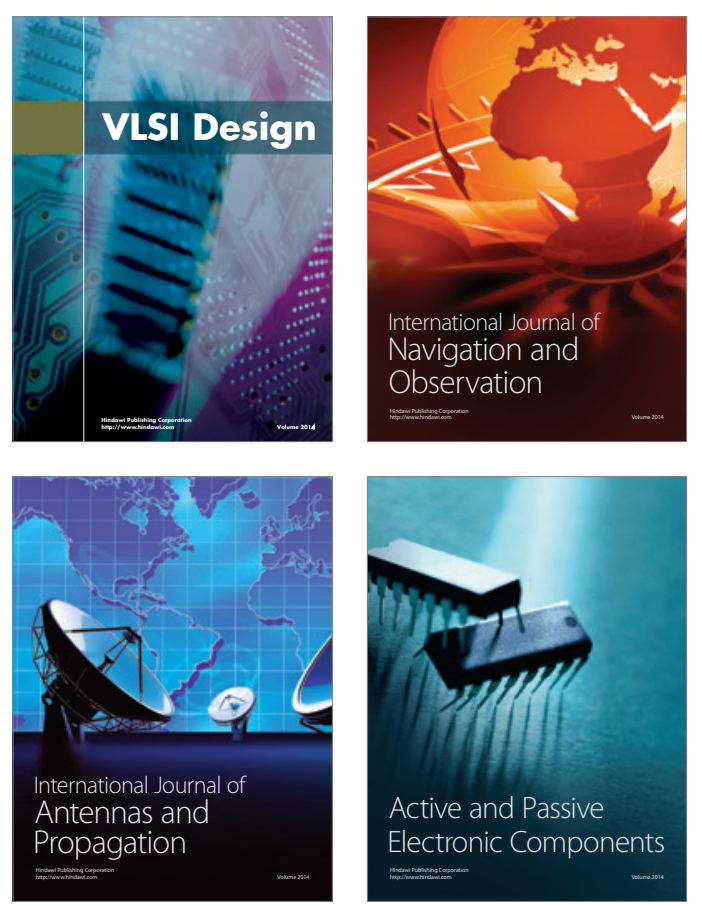
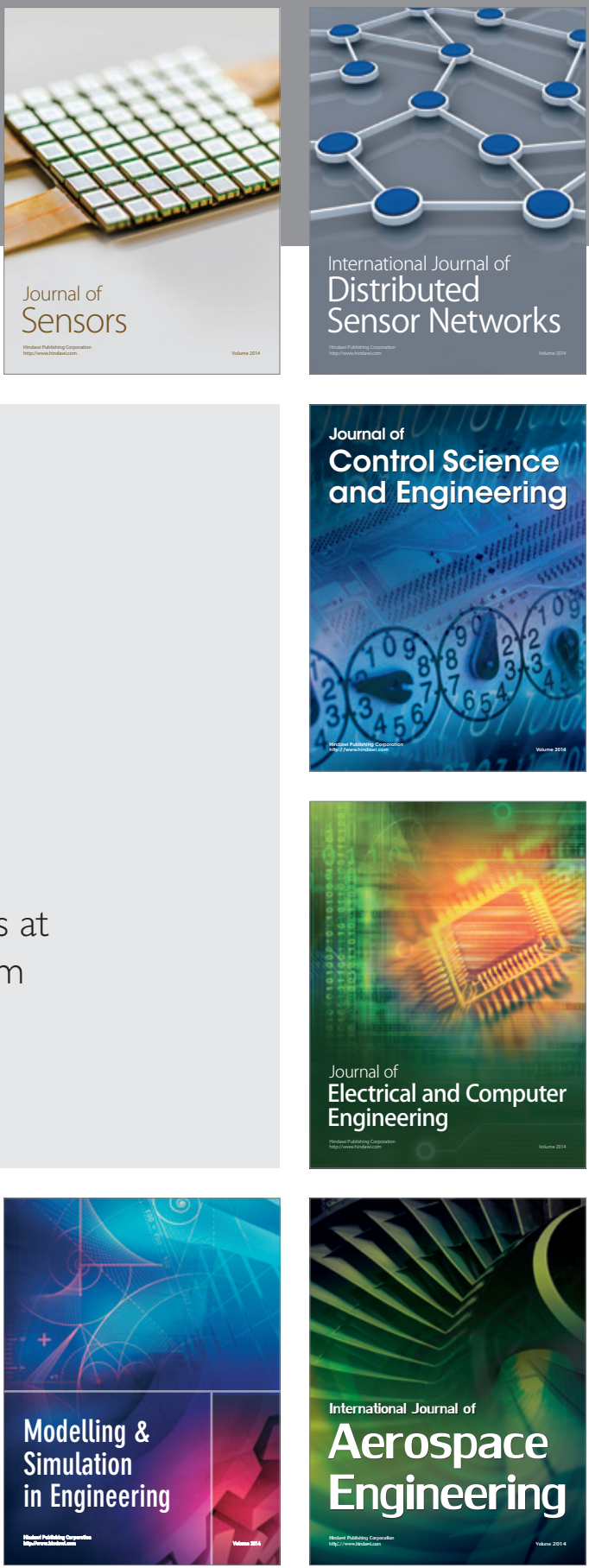

Journal of

Control Science

and Engineering
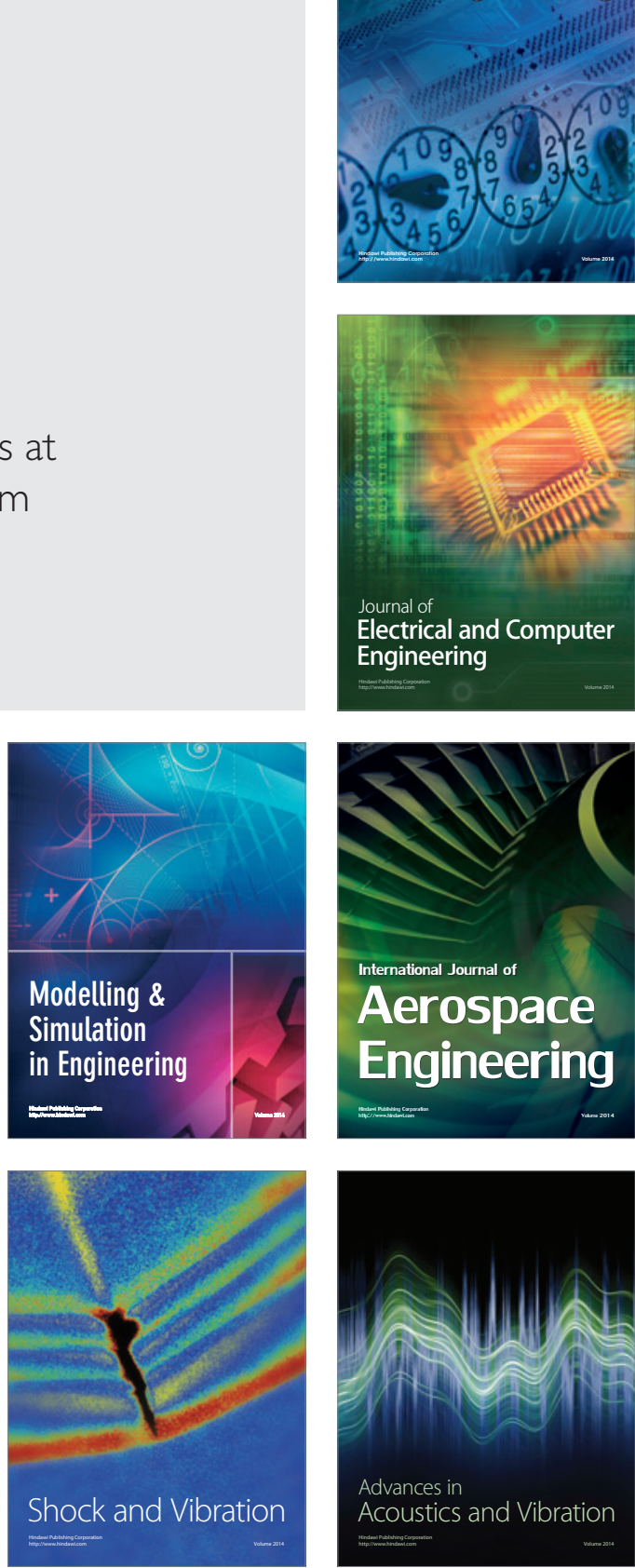